\title{
LEVANTAMENTO FLORÍSTICO DE EPÍFITOS VASCULARES DO BOSQUE SÃO CRISTOVÃO - CURITIBA - PARANÁ - BRASIL
}

\section{Rising Floristic of Vascular Epiphytes of the São Cristovão Forest, Curitiba, Parana State, Brazil}

\author{
Sonia Marisa Hefler ${ }^{1}$ \\ Paulo Faustioni ${ }^{2}$
}

\section{Resumo}

Este trabalho realizado em um remanescente de floresta Ombrófila mista do município de Curitiba consta do levantamento florístico de epífitos vasculares do Bosque São Cristóvão. A partir de coletas, análises em campo, em material de herbário, dados bibliográficos e consulta a especialistas, registra-se a ocorrência de 17 espécies epifíticas, distribuídas em cinco famílias, sendo a família Orchidaceae com maior riqueza específica. São apresentados dados sobre síndrome de polinização, dispersão, adaptações morfológicas e categorização das formas de vida.

Palavras-chave: Epífitos Vasculares; Floresta Ombrófila Mista; Levantamento.

\section{Abstract}

This work accomplished in a remainder ombrophylous mixed forest of the municipal district of Curitiba, consists of the rising floristic of vascular epiphytes of the San Cristovão Forest. Starting from collections, analyses in field, in herbarium material, bibliographical data and it consults the specialists enrolls the occurrence of 17 epiphytic species, distributed in five families, being the family Orchidaceae with larger specific wealth. Data are presented on pollination syndrome, dispersion, morphologic adaptations and types in the life ways.

Keywords: Vascular Epiphytes; Ombrophylous Mixed Forest; Rising.

1 Professora M.Sc. da Pontifícia Universidade Católica do Paraná - CCTP - Av. da União 500, Jardim Coopagro, CEP 85900-00, Toledo, Paraná, Brasil.

E-mail: sonia.hefler@pucpr.br

${ }^{2}$ Estagiário graduado em Biologia, Curitiba, Paraná. 


\section{Introdução}

A riqueza específica dos epífitos vasculares em Floresta Ombrófila Mista é similar às formações sob domínio da Floresta Ombrófila Densa e maior que em formações sob clima com estações seca e chuvosa bem definidas (BORGO, 2002).

Gentry e Dodson (1987) acreditam que existam 29.000 espécies de epífitos vasculares no planeta, o que corresponde a aproximadamente $10 \%$ de todas as plantas vasculares cientificamente conhecidas.

Dados sobre a diversidade epifítica específica em diferentes áreas de Floresta Ombrófila Mista do município de Curitiba podem ser constatados nos trabalhos de Cervi et al. (1988), 26 espécies, IAPAR (1994), 106 espécies, Dittrich, Kozera e Menezes-Silva (1999), 74 e Borgo (2002), 96 espécies nativas.

Benzing (1989, 1990) classifica os epífitos vasculares em cinco formas diferentes: quanto a relação destes com o hospedeiro, ao hábito de crescimento, ao requerimento hídrico, à necessidade fótica e ao tipo de substrato.

Quanto à dispersão, a maioria das espécies epifíticas vasculares é anemocórica, possuindo esporos (esporocoria) ou diminutas sementes (DITTRICH; KOZERA; MENEZES-SILVA, 1999). No tocante à polinização, Maison (1977) enfatizou que a polinização por animais é uma característica compartilhada por todos os epífitos magnoliofíticos, ressaltando que os mesmos possuem um sistema de polinização mais especializado e mais específico que os não epífitos, de acordo com Gentry e Dodson (1987).

Os estudos florísticos e fitossociológicos de epífitos envolvem diversos problemas, principalmente 0 acesso às copas das árvores, onde a maioria das espécies desenvolvem-se. Este, talvez, seja o principal motivo pelo qual poucos trabalhos têm sido realizados com essa interessante forma biológica de plantas (WAECHTER, 1986). Isto mostra a importância de realizar estudos florísticos e contribuir com o conhecimento epifítico da flora de Floresta Ombrófila Mista do Estado do Paraná.

\section{Materiais e métodos}

O levantamento florístico dos epífitos vasculares foi realizado no Bosque São Cristóvão, situado no bairro de Santa Felicidade, na região Oeste do Município de Curitiba. Trata-se de uma área de cerca de $24.000 \mathrm{~m}^{2}$ e apresenta-se drasticamente alterada com predomínio de Podocarpus lamberti, que demonstrou grande afinidade com várias espécies de epífitos. Até a realização deste trabalho não havia registro da diversidade de espécies epifíticas ocorrentes no local. O bosque apresenta pequenos resquícios da vegetação de Floresta Ombrófila Mista, o qual resume-se a três pequenos blocos de árvores.

Para o levantamento florístico foram realizadas visitas quinzenais ao Bosque, durante um período de oito meses, sendo então verificados e identificados 51 indivíduos arbóreos, pertencentes a seis famílias. A área amostrada equivale a cerca de $2.000 \mathrm{~m}^{2}$. Os epífitos encontrados férteis foram coletados com auxílio de tesoura de poda manual, tesoura de poda alta ou escada de alumínio de 7 metros, sendo então submetidos à herborização. Somente alguns indivíduos foram coletados, outros apenas observados in loco até o florescimento, quando possível. As espécies exóticas também foram incluídas nas análises.

O material coletado foi processado de acordo com as técnicas usuais de coleta, preparação e herborização de materiais botânicos descritas em IBGE (1992). A determinação foi efetuada com a utilização de bibliografia específica, comparação com a coleção do Herbário do Departamento de Botânica da UFPR (UPCB), ou consulta a especialistas. A validade do nome das espécies foi verificada no International Plantae name Index (2002), sendo anotadas as abreviaturas dos nomes dos autores sugeridas por Brummitt e Powell (1992).

Para a categorização das formas de vida foi utilizada a obra de Benzing (1990). A síndrome de polinização seguiu Real (1983), e as dispersões Madson (1977).

\section{Resultados}

O estudo dos epífitos vasculares foi realizado a partir da análise de 51 forófitos, pertencentes a seis famílias (TAB. 1), sendo Podocarpus lambertii Klotzsch ex Endl. (74\%) a espécie predominante da área, comprovando que a área encontra-se extremamente alterada, composta de vegetação secundária. 


\section{Tabela 1 - Forófitos vasculares registrados no Bosque São Cristóvão - Curitiba - PR}

\begin{tabular}{lll}
\hline FAMILIA & ESPECIE & $\%$ \\
\hline CANELLACEAE & Capsicodendron dinisii (Schwacke) P. Occhioni & $2 \%$ \\
ANACARDIACEAE & Lithraea brasiliensis March. & $14 \%$ \\
PODOCARPACEAE & Podocarpus lambertii Klotzsch ex Endl. & $74 \%$ \\
MYRTACEAE & Blepharocalyx salicifolius (HBK) Berg & $6 \%$ \\
ERYTHROXYLACEAE & Erythroxilum deciduum St. Hil. & $2 \%$ \\
ARAUCARIACEAE & Araucaria angustifólia (Bertol.) Kuntze & $2 \%$ \\
\hline
\end{tabular}

Na área estudada foram encontradas 17 espécies epifíticas, sendo três de Pteridophyta e 14 de Magnoliopsida (duas Magnoliopsida e 12 de Liliopsida), distribuídas em cinco famílias (TAB. 2).

Orchidaceae (oito espécies), Bromeliaceae (quatro) e Polypodiaceae (três) foram as famílias com maior riqueza específica, que juntas representaram aproximadamente $88 \%$ dos táxons observados. Das cinco famílias estudadas, Cactaceae e Piperaceae apresentaram apenas uma espécie. Dentre os gêneros com maior número de espécies destacaram-se Pleurothallis (quatro espécies); Tillandsia (três espécies).

A categoria de relação com o forófito foi a dos holoepífitos característicos, que foi registrada em todos os representantes epifíticos estudados.

As síndromes de polinização mais freqüentes foram, respectivamente, melitofilia (34\%); miofilia (24\%); não identificada (24\%) e ornitofilia (18\%) (FIG.1). A determinação das síndromes de polinização não foi possível em quatro espécimes, pois os mesmos não estavam em período de floração durante a realização do estudo e não se encontraram dados na literatura consultada.

Foram verificadas cinco síndromes de dispersão: anemocoria (46\%); endozoocoria (6\%); epizoocoria (6\%); esporocoria (18\%); pogonocoria (24\%) (FIG. 2).

A suculência nas porções vegetativas (folhas/caules/rizomas) foi registrada em Orchidaceae (70\%), Cactaceae (10\%) e Piperaceae (10\%), sendo também verificada a redução vegetativa: Cactaceae (10\%), folhas em Orchidaceae (40\%) e Piperaceae (10\%) e raízes em Bromeliaceae (40\%). A presença de velame radicial em $80 \%$ das Orchidaceae e a Poiquiloidria em 20\% das Polypodiaceae. A absorção foliar, por meio de tricomas absortivos (40\%) e o imbricamento das folhas "epífitas - tanque" (10\%), foram características exclusivas de Bromeliaceae. A presença de rizomas reptantes foi verificada em Polypodiaceae (10\%) (FIG.3).

\section{Discussão}

Nas áreas de floresta ombrófila mista estudadas em Curitiba (presente trabalho, CERVI; DO MBROW SKI, 1985; CERVI et al., 1988; DITTRICH et al., 1999; BORGO, 2002), foram registradas 20 famílias, equivalendo a $46,5 \%$ das que contêm hábito epifítico nos neotrópicos (GENTRY; DODSON, 1987).

A tendência de concentração das espécies em poucas famílias foi descrita por vários autores (MADISON, 1977; GENTRY; DODSON, 1987) como sendo conseqüência da maior especialização destas ao epifitismo. Orchidaceae, Polypodiaceae e Bromeliaceae são tradicionalmente descritas como as famílias mais ricas em espécies epifíticas em diversos Biomas (MADISON, 1977), e neste estudo totalizaram $88,2 \%$ das espécies.

Em relação à composição dos epífitos, estimativas indicam que as monocotiledôneas ocorrem cerca de cinco vezes mais do que as dicotiledôneas (BENZING, 1989). Neste estudo, as monocotiledôneas somaram $85,7 \%$ das espécies dentre as Magnoliophytas, ocorrendo cerca de seis vezes mais que as dicotiledôneas, ficando os valores dentro das estimativas. 


\section{Tabela 2 - Epífitos vasculares registrados no Bosque São Cristóvão - Curitiba - PR}

\begin{tabular}{|c|c|c|c|c|}
\hline FAMÍLIA/ ESPÉCIE & C. E. ${ }^{A}$ & POL. ${ }^{B}$ & DIS. $^{C}$ & ADAP. \\
\hline \multicolumn{5}{|l|}{ PTERIDOPHYTA } \\
\hline \multicolumn{5}{|l|}{ POLYPODIACEAE } \\
\hline Microgramma squamulosa (Kaulf.) de la Sota & HLC & NID & ESP & $\mathrm{L}$ \\
\hline Pleopeltis angusta Kunth & HLC & NID & ESP & $\mathrm{P}$ \\
\hline Polypodium hirsutissimum Raddi & HLC & NID & ESP & $\mathrm{P}$ \\
\hline \multicolumn{5}{|l|}{ MAGNOLIOPHYTA - MAGNOLIOPSIDA } \\
\hline \multicolumn{5}{|l|}{ CACTACEAE } \\
\hline Rhipsalis nevesarmondii K. Schum. & HLC & MEL & ENZ & $\mathrm{R}, \mathrm{S}$ \\
\hline \multicolumn{5}{|l|}{ PIPERACEAE } \\
\hline Peperomia catharinea Miq. & HLC & NID & EPZ & $\mathrm{R}, \mathrm{S}$ \\
\hline \multicolumn{5}{|l|}{ MAGNOLIOPHYTA - LILIOPSIDA } \\
\hline \multicolumn{5}{|l|}{ BROMELIACEAE } \\
\hline Tillandsia stricta Sol. & HLC & ORN & POG & $\mathrm{A}, \mathrm{R}$ \\
\hline Tillandsia tenuifolia $\mathrm{L}$. & HLC & ORN & POG & $\mathrm{A}, \mathrm{R}$ \\
\hline Tillandsia usneoides L. & HLC & MEL & POG & $\mathrm{A}, \mathrm{R}$ \\
\hline Vriesea reitzii Leme \& Costa & HLC & ORN & POG & $\mathrm{A}, \mathrm{R}, \mathrm{T}$ \\
\hline \multicolumn{5}{|l|}{ ORCHIDACEAE } \\
\hline Campylocentrum aromaticum Barb. e Rodr. & HLC & MEL & ANE & $\mathrm{R}, \mathrm{S}, \mathrm{V}$ \\
\hline Campylocentrum burchelli Cogn. & HLC & MEL & ANE & $\mathrm{R}, \mathrm{V}$ \\
\hline Leptotes unicolor Barb. Rodr. & HLC & MEL & ANE & $\mathrm{R}, \mathrm{S}, \mathrm{V}$ \\
\hline Oncidium sp. & HLC & MEL & ANE & $\mathrm{S}, \mathrm{V}$ \\
\hline Pleurothallis hatschbachii Schltr. & HLC & MIO & ANE & $\mathrm{S}, \mathrm{V}$ \\
\hline Pleurothallis hygrophila Barb. Rodr. & HLC & MIO & ANE & $\mathrm{S}, \mathrm{V}$ \\
\hline Pleurothallis recurva Lindl. & HLC & MIO & ANE & $\mathrm{S}, \mathrm{V}$ \\
\hline Pleurothallis sonderana $\mathrm{Rchb} . \mathrm{f}$. & HLC & MIO & ANE & $\mathrm{R}, \mathrm{S}, \mathrm{V}$ \\
\hline
\end{tabular}

(A): Categorias Ecológicas (C.E.): HL C - holoepífito característico.

(B): Síndromes de polinização (POL): MEL - melitofilia; MO - miofilia; NID - não identificada; ORN - ornitofilia.

(C): Dispersão (DIS.): ANE - anemocoria; ENZ - endozoocoria; EPZ - epizoocoria; ESP - esporocoria; POG - pogonocoria.

(D): Adaptações ao epifitismo (ADAP.): A - absorção foliar; L- rizoma reptante; R - redução de partes vegetativas; S - suculência, $\mathrm{T}$ - epífitas-tanque; $\mathrm{V}$ - presença de velame radicial P - Poiquiloidria. 
Figura 1- Síndrome de polinização verifica da nas espécies epifíticas do Bosque São Cristóvão

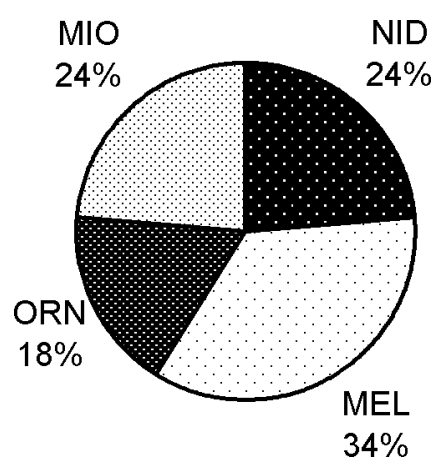

Fonte: os autores

Nota: MEL -melitofilia; MIO - miofilia; NID - não identificada; ORN - ornitofilia.
Figura 1- Dispersão verifica da nas espécies epifíticas do Bosque São Cristóvão

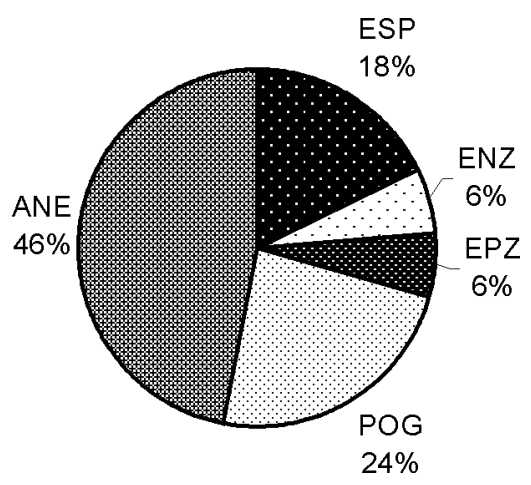

Fonte: os autores

Nota: ANE - anemocoria; ENZ - endozoocoria;EPZ - epizoocoria; ESP - esporocoria; POG - pogonocoria.

Figura 1- Adaptações morfológicas ao epifitismo verifica da nas espécies do Bosque São Cristóvão

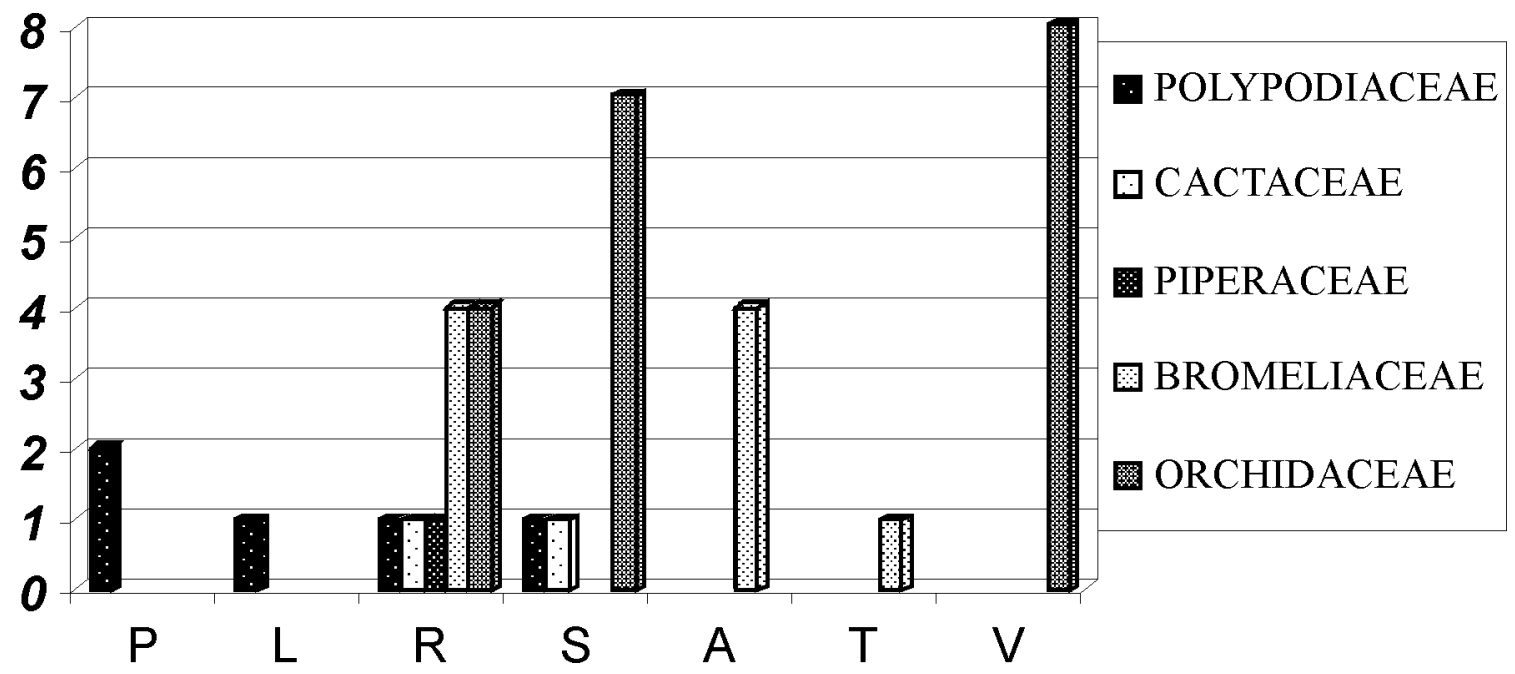

Fonte: os autores

Nota: A-absorção foliar; L - rizoma reptante; R-redução de partes vegetativas; S - suculência, T - epífitas-tanque; V - presença de velame radicial; P - Poiquiloidria 
As estratégias reprodutivas das epífitas são consideradas os principais fatores que propiciam o sucesso do grupo no dossel florestal (GENTRY; DODSON, 1987).

A síndrome de dispersão mais comum foi a anemófila (40\% das espécies), como já indicado por Benzing (1989) ao relatar que a maioria dos gêneros ocorrentes nos neotrópicos (cerca de 800) apresentam esta síndrome.

Este estudo confirma os holoepífitos característicos como sendo a categoria de relação dominante na Floresta Ombrófila Mista. Segundo Borgo (2002), a interação entre o epífito e o forófito implica diversas adaptações morfofisiológicas daquele, tendo em vista a limitação da disponibilidade de nutrientes, água e até mesmo substrato a que está submetido.

O rigor climático é considerado como um dos fatores negativos de maior impacto sobre 0 epifitismo e a disponibilidade de água, combinada de várias formas com irradiação e nutrientes, interfere fortemente no desenvolvimento de comunidades epifíticas (BORGO, 2002).

Dessa forma, toda característica que possibilite economia ou o melhor aproveitamento do recurso hídrico torna-se imprescindível (BORGO, 2002), como sugere Benzing (1989) ao afirmar que a distribuição dos epífitos nos forófitos estaria mais relacionada aos gradientes de umidade que de intensidade de luz no dossel florestal. Um exemplo disso são as denominadas "bromélias atmosféricas" que apresentam tricomas absortivos nas folhas, como também as "bromélias-tanque", que além dos tricomas absortivos possuem reservatório para acúmulo de água formado pelo imbricamento das folhas (BORGO, 2002).

Em contraposição à redução do sistema radical das bromélias, observa-se a existência de raízes bem desenvolvidas e fotossinteticamente ativas em algumas Orchidadeae (BORGO, 2002). Tal caractenística é mais evidente em Campylocentrum burchellii, espécie ocorrente no Bosque, onde as raízes suprem a ausência das folhas.

As espécies Microgramma squamulosa, Pleopeltis angusta, Polypodium hirsutissimum, Tillandsia stricta, Campylocen trum aromaticum e Pleurothallis sonderana, registradas no Bosque, segundo Borgo (2002), são encontradas em formações, com os mais variados graus de perturbação, podendo ser denominadas de generalistas ou pioneiras.
Tais espécies, consideradas r-estrategistas, aparentemente não têm limitações de sobrevivência quanto às variações microclimáticas (principalmente intensidade luminosa e umidade), tendo em vista que podem ocorrer em áreas mais abertas ou em forófitos encontrados nas bordas dos fragmentos (Borgo, 2002), fato observado no bosque.

Segundo Borgo (2002), a interferência humana também é determinante na riqueza de epífitos nos fragmentos. Nos locais em que a visitação pública é mais intensa, os epífitos são visualizados apenas a partir de $2,5 \mathrm{~m}$ do solo, sendo clara a ação de retirada destes dos forófitos, principalmente de espécies ornamentais. Esta situação também foi observada no Bosque, que é uma área de intensa visitação.

Os epífitos vasculares representam pelo menos $15 \%$ do total de espécies vegetais encontradas em Floresta Ombrófila Mista (Cervi et al, 1987; Borgo, 2002), denotando a importância deste grupo de plantas nesta unidade vegetacional.

\section{Considerações finais}

Com este trabalho conclui-se que a área, embora muito alterada, ainda mantém o ecossistema ativo, contribuindo com a diversidade vegetal epifítica (17 espécies), proporcionando interação com os polinizadores e desenvolvendo estratégias de sobrevivência.

\section{Agradecimentos}

Deixamos nossos sinceros agradecimentos a Bióloga Marilia Borgo, pelo companheirismo, profissionalismo e pelas excelentes contribuições para a realização deste trabalho.

\section{Referências}

BENZING, D. H. Vascular epiphytism in America. In: LETH, H.; WERGER, M. J. Ecosystems of the world,. Amsterdan: [s.n.], 1989. v. 14b. p. 133-154.

BENZING, D. H. Vascular epiphytes. Cambridge: Cambridge University Press, 1990.

BENZING, D. H. The physical mosaic and plant variety in forest canopies. Selbyana, v. 16, p. 159-168, 1995. 
BORGO, M. As comunidades de Epífitos Vasculares em Fragmentos Florestais no Município de Curitiba, Paraná, Brasil. Curitiba, 2002, 72f. Dissertação (Mestrado em Botânica) Setor de Ciências Biológicas, Universidade Federal do Paraná, Curitiba.

BRUMMIT, R. K.; POWELL, C. E. Authors of Plant Names. London: Royal Botanic Garden. Kew, 1992.

CERVI, A. C.; DOMBROWSKI, L. T. D. Bromeliaceae de um capão de floresta primária do Centro Politécnico de Curitiba (Paraná, Brasil). Fontqueria, v. 9, p. 9-11, 1985.

CERVI, A.C.; ACRA, L A.; RODRIGUES, L; TRAIN, S.; IVANCHECHEN, S. L.; MOREIRA, A. L. O. R. Contribuição ao conhecimento de pteridófitas de uma mata de Araucária, Curitiba, Paraná, Brasil. Acta Biológica Paranaense, v. 6, p. 77-85, 1987.

CERVI, A.C.; ACRA, L A.; RODRIGUES, L; TRAIN, S.; IVANCHECHEN, S. L.; MOREIRA, A. L. O. R. Contribuição ao conhecimento das epífitas (exclusive Bromeliaceae) de uma floresta de Araucánia do Primeiro Planalto Paranaense. Ínsula, Florianópolis, n. 18, p. 75 - 82, 1988.

DITTRICH, V.A.O.; KOZERA, C.; SILVA, S. M. Levantamento florístico dos epífitos vasculares do Parque Barigui, Curitiba, Paraná, Brasil. Iheringia Série Botânica, Porto Alegre, v. 52, p.11 - 21, 1999.
GENTRY, A. H,; DODSON, C. H. Diversity and biogeography of neotropical vascular epiphytes. Annals of the Missouri Botanical Garden, v. 74, p. 205-233, 1987.

IAPAR. Cartas climáticas do Estado do Paraná. Doc. 18. Londrina: Instituto Agronômico do Paraná, 1994.

INTERNATIONAL PLANT NAME INDEX. Disponível em: <http:www.us.ipni.org/ipni/ query_ipni.html>Acesso em 23/11/2002.

IBGE. Manual Técnico da Vegetação Brasileira. Rio de Janeiro: Fundação Instituto Brasileiro de Geografia e Estatística, DERNA, 1992.

MADISON, M. Vascular epiphytes: their systematic ocourrence and salient features. Selbyana, v. 2, p. 1-13, 1977.

REAL, L Pollination Biology. Orlando: Academic Press, 1983.

WAECHTER, J. L. Epífitos vasculares da mata paludosa do Faxinal, Torres, Rio Grande do sul, Brasil. Iheringia Série Botânica, Porto Alegre, v. 34, p. 39-49, 1986.

Recebido em/Recived in: 16/09/2003 Aprovado em/ Approved in: 10/12/2003 